\title{
IMPLEMENTASI SISTEM KONTROL DISKRIT UNTUK HYBRID SOLAR WATER HEATER MENGGUNAKAN OMRON CPM2A
}

\author{
Sri Utami, RizkyKurnia \\ Jurusan Teknik Konversi Energi - Politeknik Negeri Bandung \\ Email: utamiwu@yahoo.com, sri.utami@polban.ac.id
}

\begin{abstract}
ABSTRAK
Pemanfaatan pemanas air tenaga surya dirasakan kurang optimal karena ketergantungannya terhadap kondisi cuaca yang tidak dapat diprediksi. Pengembangan sistem hybrid yang menggabungkan solar water heater dan elemen pemanas listrik yang dikontrol secara diskrit dilakukan dalam penelitian ini. Sistem diskrit ini digunakan untuk mengurangi konsumsi daya pemanas air elektrik disamping untuk memenuhi nilai panas air yang dibutuhkan oleh konsumen.

Untuk sistem kontrol diskrit yang diusulkan, digunakan Omron CPM2A sebagai Programmble Logic Control dan LM35 sebagai sensor temperatur. Elemen pemanas listrik akan berfungsi jika air yang dihasilkan pemanas air tenaga surya didalam tangki nilai panasnya masih belum sesuai dengan set point yang diinginkan.Pengurangan konsumsi daya listrik dilakukan dengan memberikan beberapa nilai set point yaitu $100 \%, 75 \%, 50 \%$ dan $25 \%$ dari total daya yang diperlukan oleh elemen pemanas. Dengan kontrol diskrit ini sistem dapat mengurangi konsumsi energi sebesar $10.97 \%$ dibandingkan dengan sistem konvensional.
\end{abstract}

Kata kunci : pemanas air, tenaga surya, sistem hybrid, kontrol diskit, sensor temperatur

\section{ABSTRACT}

Application of solar water heater is still not optimal since it depends on unpredictable weather. This research aimed to develop hybrid system which combines a solar water heater and electric heating element that were controlled discreatly. The discrete system was used to reduced power consumption of electri water heater besides to meet consumers requirement of water from certain temperatur.

For proposed system, Omron CPM2A was used as controller for discrete system and LM 35 as temperature sensor. Electric heater element will work when water produced by solar water heater inside storage tank has heat value that still does not suit with the set point. Reduction of electric power consumption was done by giving several set point values, that were 100\%, $75 \%, 50 \%$ and $25 \%$ of the total power required by the heating element. The discrete control system was able to reduce energy consumption by $10.97 \%$ comparing with conventional.

Keywords: water heater, solar power, hybrid system, discrete control, temperature sensor

\section{PENDAHULUAN}

Dalam kehidupan sehari-hari salah satu pemanfaatan energi matahari adalah pemanas air atau solar water heater yang menggunakan prinsip dari kolektor surya yang menangkap radiasi sinar matahari. Pemanas air merupakan kebutuhan sehari-hari yang sangat vital bagi penduduk dan merupakan salah satu pengkonsumsi gas alam yang paling signifikan. Berdasarkan survey yang dilakukan oleh Residential Appliance Saturation Survey penggunaan gas alam untuk memanaskan air mencapai $49 \%$ [1]. Penelitian yang dilakukan di California ini ini juga melaporkan bahwa penggunaan gas alam untuk rumah tangga bisa turun hingga $35 \%$ untuk keperluan pemanas airnya jika mengimplementasikan desain prosedur yang sudah terimprovisasi dan menggunakan peralatan yang mempunyai efisiensi yang tinggi [2]. Peningkatan efisiensi pemanas air juga bisa diperoleh dengan menggunakan metode ini.

Qi (2006) menyebutkan solar water heater dengan teknologi yang terus berkembang telah 
digunakan lebih dari 15000000 buah di China [3]. Untuk meningkatkan performa solar water heater ini telah dilakukan beberapa penelitian mengenai hybrid solar water heater. Solar water heater dikombinasikan dengan mesin adsorption refrigation untuk memenuhi kebutuhan pemanasan air rumah tangga untuk musim yang berbeda serta meningkatkan efisiensi penggunaan energi matahari [3]. Untuk meningkatkan efisiensi, penggunaan solar water heater, dikombinasikan untuk pemanas ruangan pada musim dingin [4]. Penggunaan solar water heater untuk skala besar juga telah dilakukan dengan mengimplementasikannya untuk pemanas air pada pusat olahraga. Penelitian ini dilakukan untuk kondisi iklim hongkong dan tiga kota lain di Prancis dan dibandingkan dengan sistem pemanas konvensional [5].

Menurut penelitian [3], solar water heater (SWH) selain mempunyai manfaat juga memiliki kekurangan yaitu energi matahari yang tersedia tidak selalu dapat memenuhi kebutuhan pemanasan air. Karena itu beberapa penelitian untuk meningkatkan performa SWH agar dapat memenuhi kebutuhan pemanasan air telah dilakukan. Diantaranya dilakukan oleh Premkumar (2012) dengan menambahkan sheet dantube thermal absorber dengan solar PV module untuk mengekstraksi panas [6]. Cassard dkk (2011) dalam laporannya untuk Residential Solar Water Heating di United States menunjukkan bahwa sistem solar water heater yang di-backup dengan penggunaan gas alam mengalami penurunan pada capital costnya sebesar $\$ 2500$ [7]. Penggunaan solar water heater memberikan alternatif pengganti sumber energi fosil, terutama untuk instalasi skala besar. Sehingga perlu dicari desain yang efektif untuk dapat menggunakan SWH meskipun ketika nilai irradiasi matahari tidak terlalu tinggi.

Penelitian ini bertujuan untuk mengkombinasikan solar water heater dengan elemen pemanas elektrik yang dikontrol menggunakan Omron CPM2A sebagai sistem kontrolnya. Elemen pemanas listrik ini dikontrol secara otomatis guna mendapatkan temperatur yang ingin dicapai dari air yang keluar dari solar water heater jika set point yang diinginkan belum tercapai. Dengan penambahan sistem kontrol hybrid ini temperatur air dapat diatur sesuai keinginan pengguna meskipun nilai irradiasi matahari tidak terlalu tinggi. Kelebihan lain sistem kontrol hybrid ini adalah pengurangan konsumsi daya pemanas elektrik sehingga dapat menghemat penggunaan energi listrik.

\section{TINJAUAN PUSTAKA}

\subsection{Solar Water Heater (SWH)}

Menurut Harris (2005), Pemanas air tenaga surya adalah sebuah sistem dimana panas matahari dikumpulkan oleh kolektor surya dan digunakan untuk meningkatkan suhu cairan pentransfer panas (air atau cairan antibeku) yang mengalir melalui pipa-pipa di kolektor; panas yang terkandung dalam cairan ini kemudian disampaikan dan dipindahkan ke air domestik [8]. Sistem ini terbagi menjadi 2 yaitu sistem pemanas air tenaga surya langsung dan sistem pemanas air tidak langsung.

Pada sistem pemanas air tenaga surya langsung input air (air domestik) langsung mengalir, melewati kolektor, kemudian menuju ke tangki pasokan air panas. Sedangkan pada sistem pemanas air tenaga surya tidak langsung menggunakan sirkulasi loop tertutup dan memiliki elemen penukar panas; cairan yang mengalir melewati kolektor surya terisolasi dari kontak dengan cairan lain (air minum) pada sistem.

\subsection{Programmable Logic Controllers (PLC)}

Programmable Logic Controllers(PLC) adalah komputer elektronik yang mudah digunakan (user friendly) yang memiliki fungsi kendali untuk berbagai tipe dan tingkat kesulitan yang beraneka ragam .PLC ini dirancang untuk menggantikan suatu rangkaian relay sequensial dalam suatu sistem kontrol. Selain dapat diprogram, alat ini juga dapat dikendalikan, dan dioperasikan oleh orang yang tidak memiliki pengetahuan di bidang pengoperasian komputer secara khusus. $P L C$ ini memiliki bahasa pemrograman yang mudah dipahami dan dapat dioperasikan bila program yang telah dibuat dengan menggunakan software yang sesuai dengan jenis $P L C$ yang digunakan sudah dimasukkan.

Alat ini bekerja berdasarkan input-input yang ada dan tergantung dari keadaan pada suatu waktu tertentu yang kemudian akan meng- $O N$ atau meng-OFF kan output-output. Nilai 1 menunjukkan bahwa keadaan yang diharapkan 
terpenuhi sedangkan nilai 0 berarti keađaan yang diharapkan tidak terpenuhi. PLC juga dapat diterapkan untuk pengendalian sistem yang memiliki 120 Input Output. Jenis PLC yang digunakan adalah tipe OMRON CPM2A40CDR-A dengan total Input Output sebanyak 40.

\subsection{Sensor Temperatur LM35}

Suhu merupakan keadaan tingkat panas atau dingin pada benda, baik benda padat, cair ataupun benda gas. Tingkatan suhu pada suatu ruang dapat diukur dengan menggunakan sensor suhu yang terpasang pada ruang tersebut. Besaran suhu tidak bias langsung diterima oleh komponen elektronik, sehingga perlu perantara pengubah keadaan suhu menjadi besaran elektronik. Sensor yang digunakan adalah jenis LM35. Tiga pin LM35 menujukan fungsi masing - masing pin diantaranya, pin 1 berfungsi sebagai sumber tegangan kerja dari LM35, pin 2 atautengahdigunakansebagaitegangankeluaran atauVoutdenganjangkauankerjadari $\quad 0 \quad$ Volt sampai dengan 1,5 Volt dengan tegangan operasi sensor LM35 yang dapat digunakan antar 4 Volt sampai 30 Volt. Keluaran sensor ini akan naik sebesar $10 \mathrm{mV}$ setiap derajat.

\section{IMPLEMENTASI}

Sistem hybrid SWH-pemanas elektrik yang diusulkan seperti diagram skematik Gambar 1.

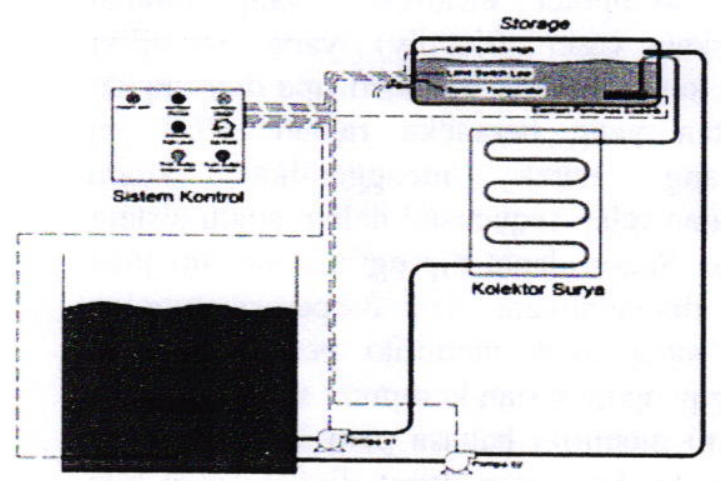

Gambar 1. Desain sistem hybrid SWH

Air berasal dari tangki air menuju ke kolektor surya menggunakan pompa. Solar water heater bekerja dengan memanfaatkan energi radiasi matahari yang diserap oleh Collector yang kemudian panas yang diserap akan ditransferkan pada air. Namun dikarenakan radiasi sinar matahari yang tidak sama dan selalu berubah-ubah, sehingga temperatur air output yang dihasilkan tidak selalu sama. Oleh karena itu dibuat sebuah sistem pemanas tambahan untuk meningkatkan dan mengatur temperatur air output sesuai dengan yang dibutuhkan.

Pemanas yang digunakan adalah pemanas elektrik yang memanfaatkan energi listrik sebagai sumber energinya. Air yang sudah melewati solar collector ini disimpan di dalam penyimpanan. Dari penyimpanan, air bisa langsung digunakan, jika sudah sesuai dengan set point yang diinginkan, atau memanfaatkan elemen pemanas, jika suhu air kurang dari set point yang diinginkan. Sebaliknya jika temperatur air melebihi set point yang diinginkan, maka pompa akan aktif dan mengalirkan air dingin untuk dicampurkan dengan air di dalam storage sampai dicapai suhu yang diinginkan.

Terdapat 4 nilai set point untuk pemanasan air menggunakan elemen pemanasan yaitu (1) $100 \%$, (2)75\%, (3) $50 \%$, dan (4) $25 \%$ dari arus elemen pemanas yang dikontrol pada sistem. Untuk set point tersebut terdapat dua skenario yang diimplementasikan pada sistem hybrid yang dibuat.

(1) Pada saat temperatur air yang masuk menuju storage lebih rendah dari set point yang telah ditentukan, maka sistem kontrol akan mengaktifkan heater hingga temperatur air didalam storage mencapai temperatur set point. Setelah set point tercapai maka sistem kontrol akan mematikan heater. Pada proses pemanasan inilah sistem kontrol hybrid diterapkan, dengan mengatur konsumsi daya heater pada beberapa kondisi yang bertujuan utuk menghemat konsumsi daya heater

(2) Ketika temperatur air yang masuk ternyata lebih tinggi dari set point yang ditentukan, sistem kontrol akan mengaktifkan pompa air pendingin yang mengalirkan air dingin menuju storage dan menurunkan temperatur air pada storage hingga mencapai set point.

Untuk sistem proteksi pada sistem solar water heater digunakan levelswitch pada storage dan tangki sumber air. Dengan menggunakan 2 buah level switch pada storage (High dan Low). Level switch low berfungsi untuk 
mengaktifkan pompa supply air dan memastikan agar air didalam storage tidak kosong sedangkan level switch high berfungsi untuk mematikan pompa supply air dan mengaktifkan sistem hybrid. Untuk level switch yang ditempatkan pada bagian bawah tangki sumber air berfungsi untuk mengnonaktifkan sistem kontrol pada saat air pada tangki kosong.

\section{HASIL DAN DISKUSI}

Pengujian dilakukan dengan membandngkan performa sistem yang diusulkan dengan kontrol on-off, pengujian dilakukan pada pukul 11.00 , dengan radiasi matahari $\pm 570 \mathrm{~W} / \mathrm{m}^{2}$ dan temperatur air 26.5 ${ }^{\circ} \mathrm{C}$. Volume pada storage digunakan sebanyak \pm 35 liter dengan elemen pemanas yang digunakan memiliki daya sebesar 600 watt. Pada pengaturan kontrol diskrit, kondisi temperatur pada rangkaian sensor temperatur diatur pada kondisi yang ditunjukkan pada Tabel 1.

Table 1 Pengaturan kontrol diskrit yang digunakan

\begin{tabular}{|c|c|c|c|}
\hline NO & $\begin{array}{c}\text { Vref } \\
(\mathbf{V})\end{array}$ & $\begin{array}{c}\text { Range } \\
\text { temperature } \\
\left({ }^{\circ} \mathbf{C}\right)\end{array}$ & Setting daya \\
\hline 1 & 2 & $20-35$ & $100 \%( \pm 600 \mathrm{~W})$ \\
\hline 2 & 3.5 & $35-37$ & $75 \%( \pm 450 \mathrm{~W})$ \\
\hline 3 & 3.7 & $37-39$ & $50 \%( \pm 300 \mathrm{~W})$ \\
\hline 4 & 3.9 & $39-$ set point & $25 \%( \pm 150 \mathrm{~W})$ \\
\hline
\end{tabular}

Pengukuran temperatur adalah temperatur air di dalam storage, sedangkan dataarus serta tegangan pada elemen pemanas diambil setiap 2 menit dimulai ketika sistem hybrid aktif hingga set point tercapai. Data tersebut diambil untuk mengamati daya yang dikonsumsi oleh elemen pemanas elektrik pada sistem kontrol hybrid.Kemudian data yang didapat dibandingkan antara sistem kotrol diskritdangan sistem kontrol on-off.

\subsection{Pengujian Sensor Temperatur}

Pengujian sensor suhu dilakukan selai untuk mengamati konversi temperatur menjad arus sekaligus untuk mengetahui akurasi hasil konversi $1^{\circ} \mathrm{C}$ menjadi 0.1 VDC pada sensor tersebut. Kenaikan tegangan yang ditunjukan pada Gambar (2), yang merupakan hasil pengukuran, linier seiring dengan naiknya temperatur air yang ditunjukan oleh termometer.

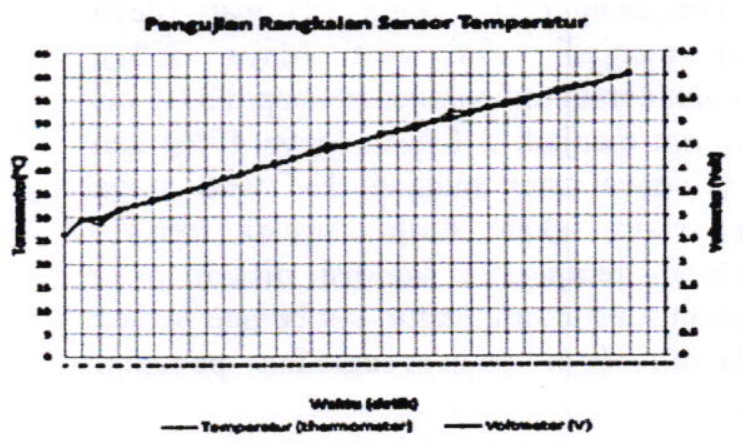

Gambar 2 Grafik Pengujian Rangkaian Sensor Temperatur

\subsection{Pengujian Konsumsi Daya}

Dari data yang didapat dari pengujian rangkaian diskrit maka dapat dibuat grafik hasil percobaan, Grafik tersebut ditunjukan pada Gambar 3.

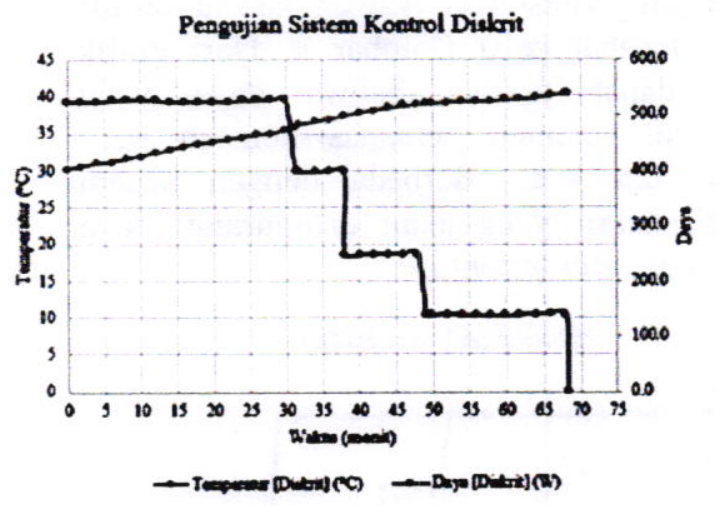

Gambar 3. Grafik Pengujian Konsumsi Daya

Pada pengujian sistem diskrit temperatur air awal pada tangki sumber air adalah $26.5^{\circ} \mathrm{C}$, setelah melewati kolektor surya temperatur yang masuk ke storage menjadi $30.2^{\circ} \mathrm{C}$. Proses peningkatan temperatur air pada storage dimulai dari temperatur $30.2^{\circ} \mathrm{C}$. Dari hasil pengujian, Grafik pengujian sistem kontrol diskrit diatas menunjukan hubungan antara kenaikan temperatur dengan konsumsi daya elemen pamanas, dapat terlihat bahwa sistem kontrol rangkaian diskrit dapat mengurangi konsumsi daya. Daya akan berkurang pada temperatur tertentu sesuai dengan grafik pada Gambar 3 sesuai dengan pengaturan kondisi diskrit pada rangkaian sensor temperatur.

Pada pengujian rangkaian diskrit ini sesuai dengan tabel 1. Pengaturan kondisi 1 pada $20^{\circ} \mathrm{C}$, kondisi 2 pada $35^{\circ} \mathrm{C}$, kondisi 3 pada $37^{\circ} \mathrm{C}$, dan kondisi 4 pada $39^{\circ} \mathrm{C}$, serta set 
point yang ditentukan adalah $40^{\circ} \mathrm{C}$. Pada grafik terlihat pada saat temperatur mencapai $35.8^{\circ} \mathrm{C}$ daya berkurang dari semula 525 watt (daya $100 \%$ menjadi 398 watt (daya $75 \%$ ), begitupun ketika temperatur mencapai $37.4 \mathrm{oC}$ daya turun menjadi 249 watt (daya $47 \%$ ) dan 39.1 oC daya turun menjadi 137 watt (daya 26\%). Daya akan turun sesuai dengan pengaturan temperatur kondisi diskrit pada rangkaian sensor temperatur dan berapa persen pengaturan daya pada rangkaian pembagi daya.

\subsection{Perbandingan Sistem Diskrit dan On- Off}

Sebagai pembanding dilakukan pengujian pada sistem on-off. Pengujian kontrol on-off dilakukan dengan temperatur awal air $30.4^{\circ} \mathrm{C}$ dan dinaikan temperaturnya menggunakan elemen pemanas elektrik hingga mencapai temperatur set point $40^{\circ} \mathrm{C}$. Perbandingan sistem yang diusulkan dengan sistem on-off seperti terlihat pada Gambar 4. Dari grafik diatas dapat terlihat bahwa daya yang dikonsumsi elemen pemanas konstan pada sekitar 525 watt. Berbeda dengan sistem kontrol diskrit yang akan mengurangi daya pada temperatur tertentu.

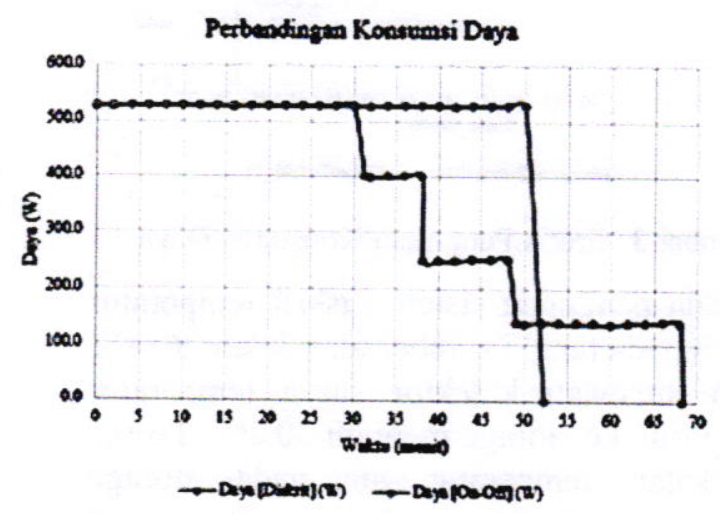

Gambar 4 Grafik Perbandingan Konsumsi Daya

Dari perbandingan konsumsi daya dapat terlihat bahwa sistem kontrol rangkaian diskrit dapat mengurangi konsumsi daya elemen pemanas elektrik pada Hybrid Solar Water Heater. Nilai energi yang diserap heater pada sistem kontrol on-off adalah sebesar 1.663.107,6 Joule. Sedangkan energi yang diserap heater pada sistem kontrol diskrit sebesar $1.480 .723,3$ Joule

\section{KESIMPULAN}

Dari pengujian yang telah dilakukan, sistem yang diusulkan dapat mengurangi penggunaan energi listrik sebesar 10,97\% jika dibandingan dengan sistem kontrol on-off. Sistem kontrol diskrit membutuhkan waktu yang lebih lama untuk mencapai temperatur set point dibandingkan dengan sistem kontrol on-off. Untuk nilai set point yang sama, sistem yang diusulkan membutuhkan waktu 68 menit 39 detik, sedangkan sistem on-off memerlukan waktu 52 menit 37 detik. Sehingga terdapat perbedaan waktu sekitar 16 menit 2 detik.

\section{REFERENSI}

[1] KEMA, Incorporated, "2009 California Residential Appliance Saturation Study", Executive Summary, California Energy Commission 2009

[2] Meister, B., 2012. " Water Heating Design Guide". California Energy Commission. Davis Energy Group Incorporated

[3] Qi, Z., 2006. "Study On Hybrid System OF Solar Powered Water Heater and Adsorption Ice Maker". International Journal on Architectural Science, Volume 6, Number 4, p.168-172

[4] Bhasin, V., 2014. "Performance Testing Methodology of a Hybrid Solar Water Heater-cum-room Lighting Room Heater"

[5] Bai, Y., Chow, TT., M'en'ezo, C. and Dupeyrat, P. 2012. "Analysis of a Hybrid PV/Thermal Solar-Assisted Heat Pump System for Sports CenterWater Heating Application". International Journal of PhotoenergyVolume 2012, Article ID 265838

[6] Premkumar, S., Ramanathan, P., Kanagaraj, R. and Prabhakar, S., 2012. "Design and Experimental Evaluation of Hybrid Photovoltaic-Thermal (PV/T) Water Heating System"

[7] Cassard,H., Denholm,P. and Ong,S. 2011. Break-even Cost for Residential Solar Water Heating in the United States: Key Drivers and Sensitivities. Technical Report .National Renewable Energy Laboratory

[8] Harris, C. M. 2005. "Dictionary of Architecture \& Construction". Mc. GrawHill. 